\title{
Association of polypharmacy and Parkinson's disease prevalence
}

\author{
Chen $\mathrm{Y}^{1}$, Yu $\mathrm{Z}^{2}$ \\ Department of Neurology, Affiliated Hangzhou First People's Hospital, Zhejiang University \\ School of Medicine, Hangzhou, China. cyq6395@sina.com
}

\begin{abstract}
OBJECTIVE: Polypharmacy and multiple diseases are common in geriatric practice; however, such kind of multiple interventions might result in adverse effects. Some previous studies have found the association of polypharmacy and Parkinson's disease, to confirm this relationship, we conducted a meta-analysis to analyze this issue quantitively.

MATERIALS AND METHODS: In total, we included 8 studies, 165,689 polypharmacy subjects and 373,660 non-polypharmacy controls, and 5644 PD patients among these subjects and controls. RESULTS: For model without any adjustment, polypharmacy group has a significantly higher prevalence than control, $\mathrm{OR}=2.53,95 \% \mathrm{Cl}[2.00,3.20](\mathrm{p}<0.001)$. However, this model showed a very high heterogeneity (I2 = $91 \%, p<0.001)$. In age, gender and disease history adjusted model, polypharmacy group has a significantly higher prevalence than control, $\mathrm{OR}=1.43,95 \% \mathrm{Cl}[1.35,1.52], \mathrm{p}<0.001$. The heterogeneity decreased to zero $\left(I^{2}=0 \%, p<0.45\right)$.

CONCLUSION: In this study we have found an association between PD risk and polypharmacy, a better designed prospective long-term cohort study might be required for further discussion on this issue (Tab. 1, Fig. 5, Ref. 14). Text in PDF www.elis.sk

KEY WORDS: polypharmacy, PD, Parkinson, meta-analysis.
\end{abstract}

\section{Introduction}

Majority of senior patients have multiple diseases; this coexistence of co-morbidity requires polypharmacy. In a previous study, $67 \%$ of senior patients $(\geq 65)$ had $\geq 2$ chronic conditions, such prevalence even increased with age, up to $81.5 \%$ for $\geq 85$ years old subjects (1). There is no way for healthcare providers but to apply polypharmacy to cover the variable conditions. However, there are concerns about such way of prescription. Multiple medications would increase the risk of potential side effects and drugdrug interactions. A previous guideline showed that to take care of an older adult with 5 common diseases would need to prescribe twelve medications (2). Limited large-scale studies have been established through this issue, which might be due to the complexity of multi-drug interactions, the risk associated with polypharmacy for persons with various conditions are not well known.

Parkinson's disease (PD) is a progressive nervous system disorder that mainly affects the motor system. It starts gradually with debilitating symptoms by resting tremor. The cause of it is largely unclear, but several risk factors were found to be associated with $\mathrm{PD}$, including pesticides, heavy metals, head injury, family history, and genetic factors (3). One of them is the impact of polypharmacy

${ }^{1}$ Department of Neurology, Affiliated Hangzhou First People's Hospital, Zhejiang University School of Medicine, Hangzhou, China, and ${ }^{2}$ Department of Cardiology, Affiliated Hangzhou First People's Hospital, Zhejiang University School of Medicine, Hangzhou, China

Address for correspondence: Zhong Yu, Department of Cardiology, Affiliated Hangzhou First People's Hospital, Zhejiang University School of Medicine, No. 261 Huansha Road, Hangzhou 310006, China. on PD as an adverse drug reaction observed in elderly people (1). To best of our knowledge, there was no study conducted as quantitively analysis for previous evidence.

\section{Material and methods}

Data sources and searches

Electronic databases including PubMed, EMBASE, Cochrane Library, Clinicaltrial.gov were searched to identify studies that reported polypharmacy associated Parkinson's disease prevalence after 2000. Following search strategies were established in PubMed:

\#1 Search ((Parkinson's disease [MeSH Terms]) OR Parkinsonism [MeSH Terms]) OR Lewy Body [MeSH Terms]

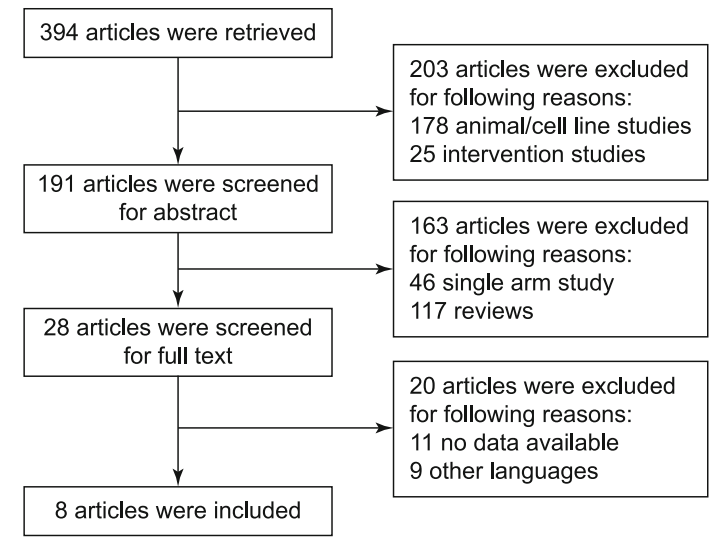

Fig. 1. Flow chart included articles. 


\begin{tabular}{|c|c|c|c|c|c|c|c|c|c|}
\hline Study or Subgroup & \multicolumn{2}{|c|}{$>=5$} & \multicolumn{2}{|c|}{$<5$} & \multicolumn{2}{|r|}{ Odds Ratio } & \multicolumn{3}{|c|}{$\begin{array}{c}\text { Odds Ratio } \\
\mathrm{M}-\mathrm{H}, \text { Random, } 95 \% \mathrm{Cl}\end{array}$} \\
\hline Gomez 2015 & 7 & 334 & 73 & 4718 & $6.2 \%$ & $1.36[0.62,2.98]$ & & 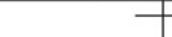 & \\
\hline Hirotoshi Niikawa,2017 & 25 & 323 & 33 & 829 & $9.7 \%$ & $2.02[1.18,3.46]$ & & & $\longrightarrow$ \\
\hline McLean 2017 & 1678 & 155945 & 962 & 352007 & $19.4 \%$ & $3.97[3.67,4.30]$ & & & - \\
\hline Onder 2013 & 14 & 95 & 41 & 604 & $7.9 \%$ & $2.37[1.24,4.55]$ & & & - \\
\hline Park 2017 & 633 & 1331 & 1214 & 5324 & $18.8 \%$ & $3.07[2.71,3.48]$ & & & $=$ \\
\hline Sganga 2015 & 16 & 238 & 7 & 242 & $5.0 \%$ & $2.42[0.98,5.99]$ & & & \\
\hline Vetrano 2018 & 188 & 2411 & 40 & 823 & $13.7 \%$ & $1.66[1.17,2.35]$ & & & - \\
\hline Total $(95 \% \mathrm{CI})$ & & 165689 & & 373660 & $100.0 \%$ & $2.53[2.00,3.20]$ & & & \\
\hline Total events & 4073 & & 3685 & & & & & & \\
\hline $\begin{array}{l}\text { Heterogeneity: } \mathrm{Tau}^{2}= \\
\text { Test for overall effect: }\end{array}$ & $\begin{array}{l}7 ; \mathrm{Chi}^{2}= \\
7.76(\mathrm{P}\end{array}$ & $\begin{array}{l}76.79 \\
<0.000\end{array}$ & $=7(P$ & $<0.000$ & 1); $I^{2}=9$ & $1 \%$ & 0.0 & $<5^{1}$ & $>=5$ \\
\hline
\end{tabular}

Fig. 2. Forest plot for polypharmacy vs control in PD prevalence, unadjusted model.

\#2 Search ((Polypharmacy [MeSH Terms]) OR Polymedication [MeSH Terms]) OR Multiple medication [key words]

Search \#1 AND \#2

Similar strategy was conducted on EMBASE, Cochrane library and Clinicaltrial.gov.

Inclusion and exclusion criteria

Inclusion Criteria: According to the previous study, we define polypharmacy as over 5 medications taken simultaneously, and Parkinson's disease diagnosis based on criteria according to ICD-10. We included observational studies discussing PD and

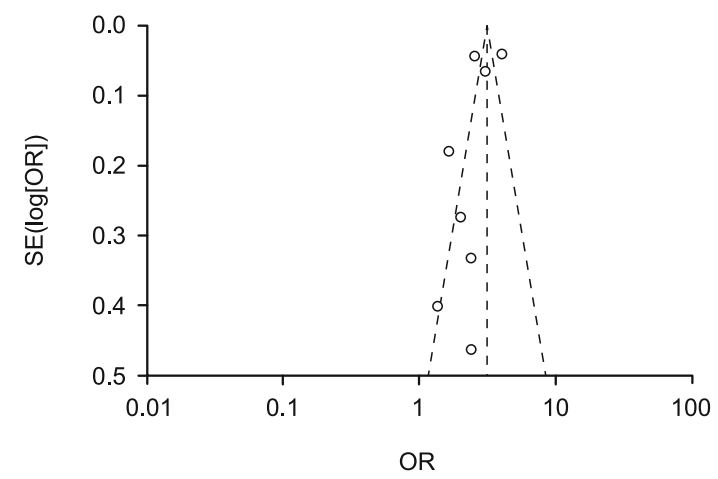

Fig. 3. Funnel plot for polypharmacy vs control in PD prevalence, unadjusted model. polypharmacy with control group (less than 5 medications), in whatever study design (retrospective or prospective); the full text of the research report should be obtained in English and it should be possible to extract data.

Exclusion Criteria: Multiple research reports of the same author at the same time as an independent study; Full text cannot be retrieved, incomplete data, or data that cannot be extracted. Animal study, reviews, Meta-analysis, etc. are not included in the study.

The flowchart is shown in Figure 1.

\section{Data extraction and statistical analysis}

The main outcome was PD prevalence in each group (polypharmacy vs non-polypharmacy), also we collected subject number, study year, study design and population information for studies' baseline characteristic. Two reviewers (Yan Chen and Zhong $\mathrm{Yu}$ ) independently conducted review for published literature. If there was any conflict in data extraction, the reviewer Zhong Yu would make a final decision. We used Revman ver 5.3 (from Cochrane library) to conduct this analysis. The heterogeneity of each study was estimated by $\mathrm{X}^{2}$ test (if $\mathrm{p}<0.05$, the difference was considered as statistically significant, and the size of the heterogeneity was determined by Q-test according to $\mathrm{I}^{2}$. If $\mathrm{I}^{2}$ is greater than $50 \%$, we would define it as high heterogeneity. All analyses would be conducted in random effect model. Also, we conducted adjusted model for covariates, including age, gender, history of cardiovascular disease or cancer.

\begin{tabular}{|c|c|c|c|c|c|c|c|}
\hline \multirow{2}{*}{$\begin{array}{l}\text { Study or Subgroup } \\
\text { Gomez } 2015\end{array}$} & \multirow{2}{*}{$\begin{array}{r}\text { log[Odds Ratio] } \\
0.5006\end{array}$} & \multirow{2}{*}{$\begin{array}{r}\text { SE } \\
0.1375\end{array}$} & \multirow{2}{*}{$\begin{array}{r}\text { Weight } \\
4.8 \%\end{array}$} & \multirow{2}{*}{$\begin{array}{c}\begin{array}{c}\text { Odds Ratio } \\
\text { IV, Random, 95\% CI }\end{array} \\
1.65[1.26,2.16]\end{array}$} & \multicolumn{3}{|c|}{$\begin{array}{c}\text { Odds Ratio } \\
\text { IV, Random, } 95 \% \mathrm{CI}\end{array}$} \\
\hline & & & & & & & $\longrightarrow$ \\
\hline Hirotoshi Niikawa,2017 & 0.6003 & 0.2576 & $1.4 \%$ & $1.82[1.10,3.02]$ & & & \\
\hline Lai 2011 & 0.3131 & 0.1019 & $8.7 \%$ & $1.37[1.12,1.67]$ & & & $\longrightarrow$ \\
\hline McLean 2017 & 0.3361 & 0.0455 & $43.4 \%$ & $1.40[1.28,1.53]$ & & & $-\frac{1}{2}$ \\
\hline Onder 2013 & 0.8643 & 0.3316 & $0.8 \%$ & $2.37[1.24,4.55]$ & & & \\
\hline Park 2017 & 0.3426 & 0.0488 & $37.8 \%$ & $1.41[1.28,1.55]$ & & & + \\
\hline Sganga 2015 & 0.8836 & 0.4627 & $0.4 \%$ & $2.42[0.98,5.99]$ & & & \\
\hline Vetrano 2018 & 0.5041 & 0.179 & $2.8 \%$ & $1.66[1.17,2.35]$ & & & $\longrightarrow$ \\
\hline Total $(95 \% \mathrm{CI})$ & & & $100.0 \%$ & $1.43[1.35,1.52]$ & & & $\boldsymbol{\nabla}$ \\
\hline \multicolumn{5}{|c|}{$\begin{array}{l}\text { Heterogeneity: } \mathrm{Tau}^{2}=0.00 ; \mathrm{Chi}^{2}=6.77, \mathrm{df}=7(\mathrm{P}=0.45) ; \mathrm{I}^{2}=0 \% \\
\text { Test for overall effect: } \mathrm{Z}=11.98(\mathrm{P}<0.00001)\end{array}$} & 0.2 & 0.5 & $>=5^{2}$ \\
\hline
\end{tabular}

Fig. 4. Forest plot for polypharmacy vs control in PD prevalence, adjusted model. 
Tab 1. Baseline characteristics for included studies.

\begin{tabular}{lccccc}
\hline Studies & Year & PD/Subject & PD/Control & Study design & Reference \\
\hline Park et al & 2017 & $633 / 1331$ & $1214 / 5324$ & Retrospective Cohort & $(5)$ \\
Vetrano et al & 2018 & $188 / 2411$ & $40 / 823$ & Prospective Cohort & $(6)$ \\
McLean et al & 2017 & $1678 / 155945$ & $962 / 352007$ & Cross-section & $(7)$ \\
Sganga et al & 2015 & $16 / 238$ & $7 / 242$ & Prospective Cohort & $(8)$ \\
Onder et al & 2013 & $14 / 95$ & $41 / 604$ & Prospective Cohort & $(9)$ \\
Gomez et al & 2015 & $7 / 334$ & $73 / 4718$ & Prospective Cohort & $(10)$ \\
Lai et al & 2011 & $1512 / 5012$ & $1315 / 9113$ & Cross-section & $(11)$ \\
Niikawa et al & 2017 & $25 / 323$ & $33 / 829$ & Cross-section & $(12)$ \\
\hline
\end{tabular}

patient (14). However, it pointed out that we still lack reliable risk estimation models, feasible interventions, and consensus of future directions. And these guidelines often provided generic practice principles or tended to provide detailed recommendations, but shockingly they neglected cognitive dysfunction in general. This is surprising since cognitive condition is highly frequent and undiagnosed in senior population. Since

\section{Results}

In total, we included 8 studies, 165,689 polypharmacy subjects and 373,660 non-polypharmacy controls, and 5644 PD patients among these subjects and controls. The baseline characteristic are listed in Table 1.

For model without any adjustment, polypharmacy group has a significantly higher prevalence than control, $\mathrm{OR}=2.53,95 \% \mathrm{CI}[2.00$, $3.20]$ ( $\mathrm{p}<0.001)$. However, this model showed a very high heterogeneity $\left(\mathrm{I}^{2}=91 \%, \mathrm{p}<0.001\right)$, as shown in forest plot and funnel plot.

After adjustment, polypharmacy group has a significantly higher prevalence than control, $\mathrm{OR}=1.43,95 \% \mathrm{CI}[1.35,1.52]$, $\mathrm{p}<0.001$. The heterogeneity decreased to zero $\left(\mathrm{I}^{2}=0 \%, \mathrm{p}<\right.$ $0.45)$ in this model.

\section{Discussion}

In this study, we have found an association between polypharmacy and risk of PD, however, because of the nature of cross-sectional study, we cannot conclude any causality in it. There was a systematic review for UK clinical guidelines discussing the potential serious drug-disease and drug-drug interactions in 11 common chronic conditions (13). They concluded that such kind of interaction is uncommon, except for those who have chronic kidney diseases. However, only a few disease specific guidelines would discuss their target patients' comorbidity, or only one comorbidity at a time. They provided few specific recommendations about how to manage people with multiple comorbidities. To cover this issue, more and more evidence of studying this topic is available, a guideline recently summarized recommendations for managing multimorbid patients, moving the focus from the disease to the

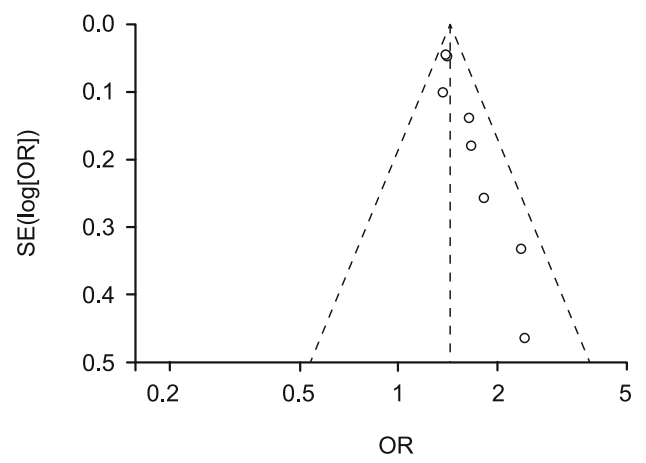

Fig. 5. Funnel plot for polypharmacy vs control in PD prevalence, adjusted model. then, this meta-analysis might be another piece of puzzle to state the polypharmacy potential risk for PD, although we still need a better designed longitudinal cohort study to prove this association.

\section{References}

1. Fried TR, O'Leary J, Towle V et al. Health outcomes associated with polypharmacy in community-dwelling older adults: a systematic review. J Am Geriatr Soc 2014; 62 (12): 2261-2272.

2. Boyd CM, Darer J, Boult C et al. Clinical practice guidelines and quality of care for older patients with multiple comorbid diseases: implications for pay for performance. JAMA 2005; 294 (6): 716-724.

3. Ball N, Teo WP, Chandra S et al. Parkinson's Disease and the Environment. Front Neurol 2019; 10: 218.

4. Wise J. Polypharmacy: a necessary evil. BMJ 2013; 347: f7033.

5. Park HY, Park JW, Sohn HS et al. Association of Parkinsonism or Parkinson Disease with Polypharmacy in the Year Preceding Diagnosis: A Nested Case-Control Study in South Korea. Drug Saf 2017; 40 (11): 1109-1118.

6. Vetrano DL, Villani ER, Grande G et al. Association of Polypharmacy With 1-Year Trajectories of Cognitive and Physical Function in Nursing Home Residents: Results From a Multicenter European Study. J Am Med Dir Assoc 2018; 19 (8): 710-713.

7. McLean G, Hindle JV, Guthrie B et al. Co-morbidity and polypharmacy in Parkinson's disease: insights from a large Scottish primary care database. BMC Neurol 2017; 17 (1): 126.

8. Sganga F, Landi F, Ruggiero C et al. Polypharmacy and health outcomes among older adults discharged from hospital: Results from the CRIME study. Geriatr Gerontol Int 2015; 15 (2): 141-146. nursing home residents with advanced cognitive impairment: results from the SHELTER study. J Am Med Dir Assoc 2013; 14 (6): 450.e7-12.

10. Gomez C, Vega-Quiroga S, Bermejo-Pareja F et al. Polypharmacy in the Elderly: A Marker of Increased Risk of Mortality in a Population-Based Prospective Study (NEDICES). Gerontology 2015; 61 (4): 301-309.

11. Lai SW, Su LT, Lin CH et al. Polypharmacy increases the risk of Parkinson's disease in older people in Taiwan: a population-based study. Psychogeriatrics 2011; 11 (3): 150-156.

12. Niikawa H, Okamura T, Ito K et al. Association between polypharmacy and cognitive impairment in an elderly Japanese population residing in an urban community. Geriatr Gerontol Int 2017; 17 (9): 1286-1293.

13. Dumbreck S, Flynn A, Nairn M et al. Drug-disease and drug-drug interactions: systematic examination of recommendations in 12 UK national clinical guidelines. BMJ 2015; 350: h949.

14. Muth C, Blom JW, Smith SM et al. Evidence supporting the best clinical management of patients with multimorbidity and polypharmacy: a systematic guideline review and expert consensus. J Intern Med 2019; 285 (3): 272-288.

Received June 21, 2020. Accepted July 27, 2020.
9. Onder G, Liperoti R, Foebel A et al. Polypharmacy and mortality among 